\section{OP0293-PARE PROBLEMS, GOALS AND URGENT WISHES OF YOUNG AUSTRIANS DIAGNOSED WITH RHEUMATIC DISORDERS: A REPORT}

\section{P. Wegscheider, G. Schaffer. Austrian Rheumatism League, Maria Alm, Austria}

Background: The Austrian Rheumatism League provides information about rheumatic disorders in order to improve the quality of life. It helps to get in contact with professional health caregivers and supports the sharing of personal experience. Because we suspected that young patients often have very different problems, goals and urgent wishes than their older counterparts, we conducted a survey addressing these questions.

Objectives: We sent a questionnaire to young people between 15 and 35 years old diagnosed with 'rheumatism' and in order to get information about their diagnosis, their daily lives, their problems, goals and urgent wishes.

Methods: 52 persons between 15 and 35 years old and diagnosed with juvenile idiopathic arthritis, rheumatoid arthritis, psoriatic arthritis, Mb. Bechterew, systemic lupus erythematodes, Sjögren-Syndrome, Sharp-Syndrome or fibromyalgia filled out a questionnaire. The subjects were divided into two groups (15-25, 2535 years). The questions covered gender, province of residence, education, job, retirement, pregnancies/family as well as the problems and goals of the subjects. We also asked where they obtain necessary information about their condition (doctor, web).

Results: $55 \%$ of the participants were $15-25$ years old and $45 \%$ were between the age of 25-35 years. $72 \%$ were female. Of these, 15 live in the province of Salzburg, 15 in Upper Austria and 15 in Vorarlberg. There were 5 participants each from other provinces (Vienna, Lower Austria, Styria, Carinthia, Tyrol and Burgenland). Most young adults got their information from their doctors $(50 \%)$ or from the internet (39\%). 39\% graduated with A-level, $27 \%$ graduated at university and $34 \%$ completed specialised job training. $78 \%$ of these young Austrians were able to earn their living; $22 \%$ were not able to work. $29 \%$ never got the chance to start working. $35 \%$ had enough support to get pregnant and to manage a family. There was a strong desire (81\%) for a meeting (which was never held before in Austrian). $50 \%$ expressed willingness to help us or to run their own group. The most urgent wish of young people diagnosed with a rheumatic disorder is to be healed or to receive the ideal therapy in order to go into remission. The participants felt that there is a lack of understanding and appreciation of young people with painful chronic diseases. Some participants would like to be treated by younger rheumatologists. They feel that this would facilitate 'eye level' consultations. There is also a lack of understanding and support in schools, in civil service settings and in government agencies. A big issue mentioned was inflexible thinking, especially in job settings. Applicants with rheumatic disorders must compete with healthy individuals for forty-hour jobs. For people with a rheumatic disorder a forty-hour job is often too much, but they can do good work in a job with shorter working hours. Young people feel it is necessary to force our society and our doctors to feel responsible for the concerns of young people with rheumatism.

Conclusions: Following the positive feedback the Austrian Rheumatism League organised a first meeting for those young people with rheumatism. A program of sports and relaxation in a beautiful natural setting was planned with the aim of enhancing positive, constructive thinking and well-being. We must encourage young people with rheumatic disorders to participate in the activities of the Austrian Rheumatism League, and encourage our society to give up black and white thinking. Everyone should be educated to accept and appreciate handicapped colleagues in their work setting, and to treat them as equals. Furthermore, our government should make it possible for persons with rheumatic disorders to stay at work and with their families even if they are not able to work forty hours a week. All doctors working with rheumatic patients should be familiar with their thoughts, beliefs, aims and problems in order to support them not only with drug prescriptions but also with understanding.

Disclosure of Interest: None declared

DOI: 10.1136/annrheumdis-2018-eular.1208

\section{OP0294-PARE ADDRESSING KEY CHALLENGES OF LAY INVOLVEMENT IN MUSCULOSKELETAL RESEARCH: CO-APPLICANTS AND TRIAL STEERING COMMITTEES}

A. Higginbottom, S. Blackburn, R. Taylor, C. Rhodes, L. Campbell, K. Dziedzic Research Institute for Primary Care and Health Sciences, Keele University, Keele, UK

Background: Patient and Public Involvement (PPI) in research is a requirement of funding in the UK. It has shown to improve the relevance and quality of research. For over 10 years, a Research User Group (RUG) of over 100 patients with musculoskeletal and other long term conditions who actively work with a Research Institute. ${ }^{1}$ Researcher and anecdotal feedback from RUG members and researchers have highlighted two challenging PPI roles: lay co-applicants on research grants and lay membership of trial study steering committees (TSCs).
For some RUG members, this has resulted in a less positive experience and a disinterest in having these important roles in the future

Objectives: To address the challenges of involving RUG members as co-applicants and as members of TSCs, and to describe ways of supporting RUG members in these roles.

Methods: Information to improve understanding of the challenges of these roles were gathered during group meetings and informal conversations with 13 RUG members, and a workshop with 35 researchers. PPI and researcher perspectives were captured on flipcharts, notes and meeting minutes. This information shaped the development of resources and approaches to support RUG members as lay co-applicants and TSC members.

Results:

Abstract OP0294PARE - Table 1. Challenges and support of lay co-applicants and TSC lay members

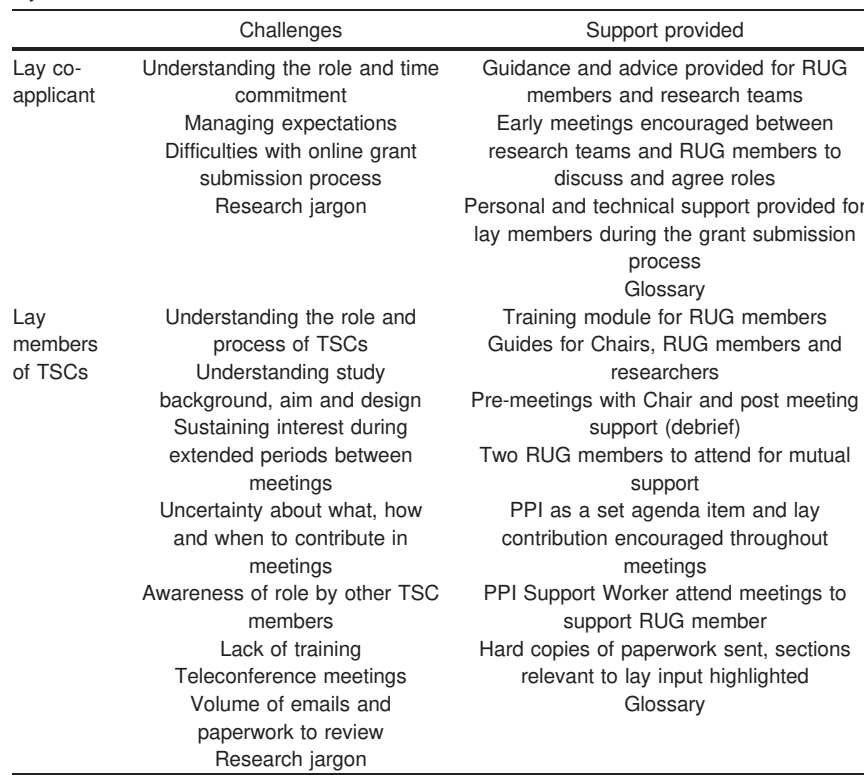

Conclusions: Providing support to RUG members and researchers can sustain active and long-term lay involvement in these challenging yet important research roles.

\section{REFERENCE:}

[1] Jinks, et al. Res Involv Engagem 2016;2:1.

Acknowledgements: We thank all RUG members for their contribution to our research, and R Taylor, C Ingram, C Walker, S Dent, P Callaghan for their input to training and guidance. We thank the Primary Care Consortium and Arthritis Research UK for supporting the RUG. KD is part-funded by a NIHR Knowledge Mobilisation Research Fellowship (KMRF-2014-03-002).

Disclosure of Interest: None declared

DOI: 10.1136/annrheumdis-2018-eular.6328

\section{OP0295-PARE 'KWEEK BEGRIP': THE LAUNCH OF OUR CREATIVE CAMPAIGN ACROSS THE NETHERLANDS ON WORLD ARTHRITIS DAY AIMS TO INCREASE AWARENESS ABOUT RMDS IN GENERAL AND PEOPLE LIVING WITH RMDS IN PARTICULAR}

\section{S. De Jong. Patient advocacy, Dutch Arthritis Foundation, Amsterdam Netherlands}

Background: With two million patients, RMDs are one of the most common chronic diseases in the Netherlands. A 2016 Nivel survey showed that $50 \%$ of all RMD patients deal with people who know too little about RMDs in order to understand their situation. RMDs are not always visible, and symptoms may vary from day to day. This often leads to friends, colleagues, neighbours and even relatives showing incomprehension. For RMD patients this can lead to loneliness, insecurity and a sense of not being accepted. Understanding RMDs and being able to show compassion starts with knowing about RMDs.

Objectives: By launching a national creative campaign about incomprehension, the Dutch Arthritis Foundation aims to raise general awareness of RMDs to promote understanding of people with a RMD and to reduce their sense of loneliness. 
Methods: The Dutch Arthritis Foundation started its campaign on World Arthritis Day: 'Grow awareness, plant a bulb!'. To 'grow understanding', we created two special tulip bulb fields, one online and one offline, for participants to plant the special 'Anita Witzier' tulip bulb. Anita Witzier is a well-known Dutch television host who suffers from rheumatoid arthritis. She has been ambassador for the Dutch Arthritis Foundation since 2001.

With the help from $70 \%$ of all local RMD patient organisations and a number of garden centres, we handed out a total of 15000 bags of tulip bulbs across the Netherlands. The campaign kick-off was on World Arthritis Day. The event, held on a tulip breeder's field, hosted presentations about incomprehension, and served to share real-life stories.

We also developed a website where people could plant bulbs digitally. Every week, participants receive a video, cartoon, update or article with information about RMDs. The campaign will run until 21 May 2018 when the (real-life) tulips will bloom in our RMD field. All participants can then visit the field to pick a bunch of flowers.

Results: The campaign received a great deal of national media attention on WorldArthritisDay, and featured on television programmes, in newspapers and on online platforms. 8000 people have since signed up for the online tulip field, sharing the information with others in their network. The campaign site drew 68000 visitors between $120 \mathrm{c}$ and $310 \mathrm{c}$ tober. The campaign also resonated with people on Facebook. In October, our campaign posts reached 1,869,000 visitors, with more than 65000 interactions (respond, share, like, watch video, conversion to campaign site).

Conclusions: Raising awareness for incomprehension can be difficult. A creative approach can help to kickstart a public debate. Responses generally show that people with RMDs appreciate this complicated subject being put on the map.

Disclosure of Interest: None declared

DOI: 10.1136/annrheumdis-2018-eular.5271

\section{OP0296 THE RISK OF DELIBERATE SELF-HARM IN RHEUMATOID ARTHRITIS AND ANKYLOSING SPONDYLITIS: A POPULATION-BASED COHORT STUDY}

B Kuriya $^{1,2}$, J. Widdifield ${ }^{3,4}$, J. Luo $^{4}$, S. Vigod ${ }^{4,5}$, N. Haroon ${ }^{1,6}$. ${ }^{1}$ Medicine, University of Toronto; ${ }^{2}$ Rheumatology, Sinai Health System; ${ }^{3}$ Holland Musculoskeletal Research Program, Sunnybrook Research Institute, University of Toronto; ${ }^{4}$ Institute of Clinical Evaluative Sciences; ${ }^{5}$ Psychiatry, University of Toronto; ${ }^{6}$ Rheumatology, University Health Network, Toronto, Canada

Background: Inflammatory arthritis is associated with the development of mental health disorders. However, there is limited data on the risk of serious mental health outcomes following a rheumatoid arthritis (RA) or ankylosing spondylitis (AS) diagnosis.

Objectives: To estimate the risk of deliberate self-harm in patients with ankylosing spondylitis or rheumatoid arthritis compared with the general population. Methods: We evaluated population-based cohorts of RA $(n=53,240)$ and AS $(n=13,964)$, each matched $1: 4$ by age, sex, and calendar year (at diagnosis) with non-IA comparator cohorts in Ontario, Canada. Individuals with a history of mental illness or prior episode of deliberate self-harm were excluded. The outcome was a first emergency room presentation for deliberate self-harm, subsequent to RA or AS diagnosis, between April 1, 2002 and March 31, 2016. We estimated hazard ratios (HR) and 95\% confidence intervals $(95 \% \mathrm{Cl}$ ) for RA and AS, separately, versus the comparator groups, adjusting for demographic, clinical and health service utilisation variables.

Results: Individuals with AS were more likely to deliberately self-harm (incidence rate [IR] of 6.79/10,000 person years [PY] compared to 3.19/10,000 PY in comparators, with an adjusted $\mathrm{HR} 1.82$ (95\% $\mathrm{Cl}: 1.26$ to 2.62). Deliberate self-harm was also increased for individuals with RA (IR 3.51/10,000 PY) compared to comparators (IR 2.45/10,000 PY) only before (HR 1.43, 95\% Cl: 1.16 to 1.75 ), but not after covariate adjustment (HR $1.09,95 \% \mathrm{Cl}: 0.88$ to 1.36). The most frequent method of self-harm was poisoning ( $64 \%$ of attempts in AS, $81 \%$ in RA) or self-mutilation (36\% in AS, $18 \%$ in RA).

Conclusions: There is a significantly increased rate of self-harm attempt in inflammatory arthritis and the risk is particularly elevated following a diagnosis of AS. These findings highlight the need for routine evaluation of self-harm behaviour as part of the management of chronic inflammatory arthritis. Understanding the mechanisms contributing to deliberate self-harm attempts will help tailor preventive strategies to reduce morbidity associated with this serious mental health outcome.

Acknowledgements: This work was funded by the Division of Rheumatology Pfizer Research Chair, University of Toronto

Disclosure of Interest: None declared

DOI: 10.1136/annrheumdis-2018-eular.3004

\section{FRIDAY, 15 JUNE 2018}

\section{More money or more education and collaboration?}

\section{OP0297 DISEASE ACTIVITY IN RHEUMATOID ARTHRITISPATIENTS IS INFLUENCED BY COUNTRIES SOCIOECONOMICS: RESULTS FROM THE METEOR REGISTRY}

S.A. Bergstra ${ }^{1}$, J. Tavares-Costa ${ }^{2}$, M. Garzo-Elizondo ${ }^{3}$, K. Salomon-Escoto ${ }^{4}$ N. Govind ${ }^{5}$, C. Allaart ${ }^{1}$, R. Landewé6. ${ }^{1}$ Rheumatology, LUMC, Leiden, Netherlands; ${ }^{2}$ Unidade Local de Saúde do Alto Minho, Ponte de Lima, Portugal; ${ }^{3}$ Hospital Universitario Dr José Eleuterio Gonzáles, Monterrey, Mexico; ${ }^{4}$ UMass Memorial Medical Center, Worcester, USA; ${ }^{5}$ University of the Witwatersrand, Johannesburg, South Africa; ${ }^{6}$ ARIC, Amsterdam, Netherlands

Background: The treatment and prognosis of rheumatoid arthritis (RA) patients have improved tremendously, but patients across the world may not benefit similarly. One of the potentially critical factors may be poorer access to expensive biologic (b)DMARDs.

Objectives: To investigate daily practice data regarding bDMARD-use in different countries worldwide and assess if a lower country's socioeconomic status (SES) is associated with worse clinical outcomes and lower usage of bDMARDs.

Methods: Data on disease activity and drug use from countries that contributed $\geq 100$ RA patients after 1-1-2000 were extracted from the daily practice, observational METEOR database. Missing data were imputed using multivariate normal imputation (30 cycles). Gross domestic product (GDP) per capita in international dollar (Int|\$) was used as indicator of SES. Per country average DAS28 and the proportion of patients in DA28-remission (DAS28 <2.6) were calculated by taking the average of all patients at the last available visit. Univariable logistic regression analyses were performed to assess associations between GDP, bDMARD use and disease outcomes at a country level.

Results: In total, 20.379 patients were included from 12 countries: United States, Mexico, South-Africa, Japan, Brazil, United Kingdom, Spain, Ireland, Portugal, France, India and the Netherlands. The number of patients ever using a bDMARD varied between $0.9 \%$ (South-Africa) and $75 \%$ (Ireland). The proportion of patients in remission at the final visit varied between $2 \%$ (India) and 39\% (Netherlands). Patients in countries with a higher GDP per capita had a lower average DAS28 and consequently, a higher proportion of them were in DAS28-remission: $\beta$ $(95 \% \mathrm{Cl})-0.32(-0.41 ;-0.021)$ lower DAS28 and an additional $4.2 \%(0.14 ; 8.26)$ of patients in DAS28-remission for every 10.000 Int|\$ additional GDP.

To underscore the assumption that the association between SES and DAS28 is mediated by bDMARD use, we assessed whether SES was associated with bDMARD use per country. Indeed, a higher GDP per capita was associated with a higher proportion of patients using a bDMARD: $\beta(95 \% \mathrm{Cl}) 11.2(4.82 ; 17.5)$, indicating an additional $11 \%$ of patients using a bDMARD per $10.000 \mathrm{Int} \mid \$$ increase in GDP per capita. Furthermore, DAS28 was $\beta(95 \% \mathrm{Cl})-0.14(-0.28 ;-0.0054)$ lower and $2.8 \%(-0.13 ; 5.8)$ more patients achieved DAS28-remission per 10\% increase in proportion of patients using a bDMARD, figure 1 .
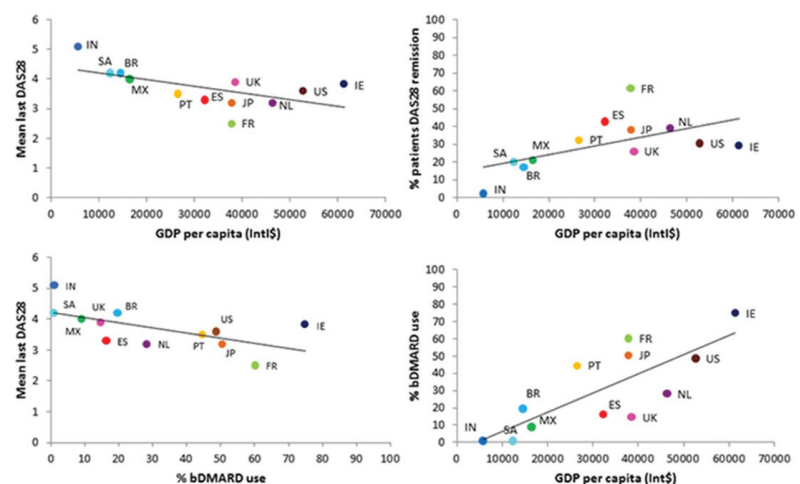

Abstract OP0297 - Table 1 Associated between 'GDP per capita (Int|\$), ‘\% bDMARD use’ and 'disease activity'.

Conclusions: RA patients in countries with a lower SES had worse disease activity. Although patients in countries with a lower SES less often used bDMARDs, the effect of bDMARD use on disease activity was smaller than expected, indicat ing that other factors than access to bDMARDs may contribute to the effectiveness of RA treatment.

Disclosure of Interest: None declared

DOI: 10.1136/annrheumdis-2018-eular.5456 